\title{
Dynamic Changes of Plasma Neutrophil Gelatinase-Associated Lipocalin Predicted Mortality in Critically III Patients with Systemic Inflammatory Response Syndrome
}

\author{
Azrina Md Ralib, Suhaila Nanyan, Mohd Basri Mat Nor \\ Department of Anaesthesiology and Intensive Care, Kulliyyah of Medicine, International Islamic University Malaysia, Pahang, Malaysia
}

Abstract

Background and Aims: About 50\% of patients admitted to the Intensive Care Unit have systemic inflammatory response syndrome (SIRS), and about $10 \%-20 \%$ of them died. Early risk stratification is important to reduce mortality. Plasma neutrophil gelatinase-associated lipocalin (NGAL) is increased by inflammation and infection. Its ability to predict mortality in SIRS patients is of interest. We evaluated the ability of serial measurement of NGAL for the prediction of mortality in critically ill patients with SIRS. Materials and Methods: This is a secondary analysis of a single-center, prospective, observational study. Patients who fulfill the SIRS criteria were recruited in the study. Delta NGAL at 24 and $48 \mathrm{~h}(\triangle \mathrm{NGAL}-24$ and $\triangle$ NGAL-48) was defined as 24 and $48 \mathrm{~h}$ NGAL minus day 1 NGAL; NGAL clearance (NGALc) was defined as percentage of $\triangle$ NGAL over day 1 NGAL. The primary outcome of the study is in-hospital mortality. Results: A total of 151 patients were analyzed, of which 53 (35\%) died. Nonsurvivors were older (51 vs. 45, $P=0.03)$ and had higher Sequential Organ Failure Assessment $(9 \pm 7$ vs. $7 \pm 4$, $P=0.02)$ and Simplified Acute Physiology Score II ( $47 \pm 15$ vs. $40 \pm 15, P=0.01)$ scores as compared to survivors. NGAL concentrations over 3 days were higher in nonsurvivors compared to survivors (repeated measures analysis of variance, $P=0.02$ ). Day 1 NGAL, $\triangle$ NGAL-24, and NGALc-24 were not independently predictive of mortality. However, day 3 NGAL, $\triangle$ NGAL-48, and NGALc-48 were predictive after adjusted for age and severity of illness (odds ratio 9.1 [1.97-41.7]). Conclusions: NGAL dynamics over $48 \mathrm{~h}$ independently predicted mortality in critically ill patients with SIRS. This could assist clinicians in risk stratification of this group of high-risk patients.

Key words: Mortality, neutrophil gelatinase-associated lipocalin, sepsis, systemic inflammatory response syndrome

\section{INTRODUCTION}

About $50 \%$ of patients admitted to the Intensive Care Unit (ICU) have systemic inflammatory response syndrome (SIRS) ${ }^{[1,2]}$ Of these, $30 \%$ have or eventually develop sepsis. ${ }^{[1,3]}$ Mortality rates in critically ill patients with SIRS are high, ranging from $10 \%$ to $20 \%$. Early risk stratification is important to reduce mortality. This will assist clinicians in reevaluation and intensification of therapy, which could prevent progression of organ failure and the associated increased in mortality.

Neutrophil gelatinase-associated lipocalin (NGAL) is a small molecule of $25 \mathrm{kDa}$, which is covalently bound to gelatinase from neutrophils and expressed at low concentrations in several human tissues, including kidneys, lungs, stomach, and colon. NGAL binds to iron through its siderophores; it can deplete bacterial iron and plays an important role in immunity to bacterial infection. It also has a role in kidney development and

\begin{tabular}{|l|l|}
\hline \multicolumn{2}{|c|}{ Access this article online } \\
\hline Quick Response Code: & Website: \\
\hline & www.ijccm.org \\
\hline
\end{tabular}

may promote cellular repair. ${ }^{[4-7]}$ NGAL expression is markedly induced by inflammation, such as in acute bacterial infections, severe sepsis and septic shock, asthma or chronic obstructive airway disease, or emphysematous lung. ${ }^{[6,8,9]}$

Plasma NGAL utility in prediction of mortality has been investigated in several studies. ${ }^{[10-14]}$ NGAL was not predictive of mortality in three studies. ${ }^{[10,11,14]}$ However, in another two studies, NGAL was fairly predictive. ${ }^{[12,13]}$ We showed that NGAL was not independently predictive of mortality in our previous study. ${ }^{[15]}$ The limitation of that study was that we

Address for correspondence: Dr. Mohd Basri Mat Nor, Department of Anaesthesiology and Intensive Care, Kulliyyah of Medicine, International Islamic University Malaysia, Jalan Sultan Ahmad Shah, 25200 Kuantan, Pahang, Malaysia. E-mail: basri.matnor@gmail.com

This is an open access article distributed under the terms of the Creative Commons Attribution-NonCommercial-ShareAlike 3.0 License, which allows others to remix, tweak, and build upon the work non-commercially, as long as the author is credited and the new creations are licensed under the identical terms.

For reprints contact: reprints@medknow.com

How to cite this article: Ralib AM, Nanyan S, Mat Nor MB. Dynamic changes of plasma neutrophil gelatinase-associated lipocalin predicted mortality in critically ill patients with systemic inflammatory response syndrome. Indian J Crit Care Med 2017;21:23-9. 
only analyzed on admission plasma NGAL concentration. Of interest is how the dynamic of NGAL changes as a tool of mortality prediction as has been shown previously that single measurements of biomarkers were not predictive; however, their dynamic concentrations were predictive. ${ }^{[16-18]} \mathrm{A}$ further analysis looking at the dynamic of NGAL over several days for prediction of mortality may be of interest.

\section{Materials and Methods}

This was a secondary analysis of a single-center, prospective, observational study of Hospital Tengku Ampuan Afzan, Kuantan, Pahang, Malaysia. The study was an extension of the BOSS-ICU study, ${ }^{[18]}$ registered under the National Medical Research Register (NMR-11-1102-9248). The study was approved by the Medical Research and Ethics Committee. Only patients with available NGAL data measured serially for the first 3 days were included in this analysis. Detail of the NGAL analysis measured on ICU admission has been published elsewhere. ${ }^{[15]}$ All consented patients aged above 18 years with established SIRS based on the criteria defined by the American College of Chest Physician/Society of Critical Care Medicine (ACCP/SCCM) were recruited in the study. ${ }^{[19]}$ SIRS is defined by the presence of at least two of the following four indicators: (1) A body temperature above $38.0^{\circ} \mathrm{C}$ or below $36.0^{\circ} \mathrm{C}$; (2) a heart rate above 90 beats/ min; (3) a respiratory rate above 20 breaths/min; (4) a white blood cell count higher than 12,000 or lower than 4000 cells/ $\mu \mathrm{l}$ or more than $10 \%$ immature (band) form. ${ }^{[19]}$ Consent from legally accepted representative was taken as the patients were mostly unconscious or undergoing resuscitation. Patients with age $<18$ years, no written consent, or who had received antibiotics for more than $24 \mathrm{~h}$ before screening were excluded from the study.

Blood samples were collected within $24 \mathrm{~h}$ of ICU admission and daily for 3 consecutive days. The samples were centrifuged at $3600 \mathrm{rpm}$ for $15 \mathrm{~min}$ and the plasma were stored at $-80^{\circ} \mathrm{C}$. Plasma NGAL was analyzed using the Triage $^{\circledR}$ NGAL Test (Biosite, San Diego, USA). ${ }^{[20]}$ Plasma electrolytes were analyzed using the Olympus AU2700TM chemistry-immunoanalyzer (Olympus, Philadelphia, USA). NGAL kinetics is expressed as delta NGAL ( $\triangle$ NGAL). $\triangle$ NGAL at 24 and $48 \mathrm{~h}$ ( $\triangle$ NGAL-24 and $\Delta$ NGAL-48) was defined as 24 and $48 \mathrm{~h}$ NGAL minus day 1 NGAL. NGAL clearance (NGALc) at 24 and $48 \mathrm{~h}$ (NGALc-24 and NGALc-48) was defined as the percentage of $\triangle$ NGAL-24 and $\triangle$ NGAL-48 to day 1 NGAL. The primary outcome of the study is in-hospital mortality.

\section{Statistical analysis}

Statistical analysis was performed using PASW ${ }^{\circledR}$ version 18.0 (IBM, Somers, New York, USA), and PRISM 5.0 (Graph Pad, La Jolla, California, USA). Results are presented as mean \pm standard deviation for normally distributed variables or median (interquartile range) for nonnormally distributed variables. Comparison of variables between the two groups was analyzed using independent $t$-test for normally distributed variables or Mann-Whitney test for nonnormally distributed variables. Differences between three groups were analyzed using one-way analysis of variance, with post hoc least significant difference analysis. Categorical variables were compared with Chi-square test. The diagnostic and predictive performance of NGAL were assessed by area under the curve (AUC) of receiver operating characteristic (ROC) curve of the sensitivity versus 1 -specificity. ${ }^{[21]}$ The optimal cutoff point was defined as the measured quantity, which maximized sensitivity and specificity. ${ }^{[22]}$ The differences of the AUC were analyzed using DeLong method. ${ }^{[23]}$ Survival analysis was performed using Kaplan-Meier and Cox regression survival analyses for calculation of hazard ratios (HRs). All AUC, HR, and integrated discrimination improvement were presented with $95 \%$ confidence intervals.

\section{RESULTS}

A total of 151 patients were included in the study. Of these, $53(35.1 \%)$ died in the hospital. Mortality increases with increasing number of SIRS criteria (Chi-square test, $P=0.05$; Table 1). Comparing between each stage, the differences in mortality were significant only between 2 and 4 SIRS criteria $(P=0.04)$. Table 2 compares the baseline demographic, clinical characteristics, and outcome between patients' survivors and nonsurvivors. Nonsurvivors were older and had higher Sequential Organ Failure Assessment (SOFA) and Simplified Acute Physiology Score II (SAPS II) scores as compared to survivors.

\section{Temporal profile of neutrophil gelatinase-associated lipocalin for 3 days}

The temporal profile of NGAL between survivors and nonsurvivors is shown in Figure 1. NGAL concentrations were consistently higher in nonsurvivors compared to survivors from day 1 to day 3 (Mann-Whitney test, $P<0.04$ ). $\triangle$ NGAL and NGALc at $48 \mathrm{~h}$ ( $\triangle$ NGAL-48 and NGALc-48) were higher in nonsurvivors compared to survivors. In contrast, there were no differences in NGAL kinetics at $24 \mathrm{~h}$ [Table 3].

\section{Prediction of mortality}

The AUC of the ROC curve for prediction of mortality is shown in Figure 2 and Table 4. Day 1-3 NGAL were moderately predictive of mortality with AUC of $>0.60$.

\begin{tabular}{|c|c|c|c|}
\hline $\begin{array}{l}\text { Number of } \\
\text { SIRS criteria }\end{array}$ & $\begin{array}{l}\text { Number of } \\
\text { patients }\end{array}$ & $\begin{array}{l}\text { Death, } \\
n(\%)\end{array}$ & $P$ \\
\hline 2 & 89 & $25(28.1)$ & 0.05 \\
\hline 3 & 50 & $21(42.0)$ & \\
\hline 4 & 12 & $7(58.3)$ & \\
\hline
\end{tabular}


NGAL kinetics at $48 \mathrm{~h}$ ( $\triangle$ NGAL-48 and NGALc-48) but not $24 \mathrm{~h}$ was predictive of mortality. The differences of the AUC between static and dynamic NGAL are presented in Table 5 . Of these, the differences between day 1 and day 3 NGAL were significant $(-0.05[-0.1--0.001], P=0.04)$. For dynamic NGAL, the differences were significant for NGAL kinetics at

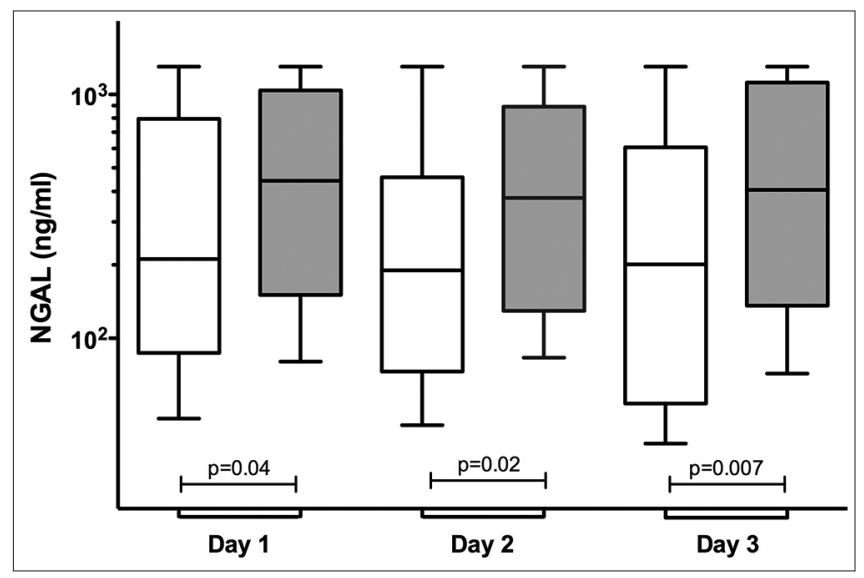

Figure 1: Temporal profiles of plasma neutrophil gelatinase-associated lipocalin concentration between survivors and nonsurvivors within the first 3 days of Intensive Care Unit admission. Mann-Whitney test, $P=0.04$ (day 1), $P=0.02$ (day 2), and $P=0.007$ (day 3). Repeated Measures analysis of variance showed the difference between subjects, $P<0.0001$, and within subjects, $P=0.28$.
24 versus $48 \mathrm{~h}$, with $P=0.03$ for both. When comparing static versus dynamic NGAL, differences were only shown for day 3 NGAL versus $\triangle$ NGAL-24 $(P=0.04)$.

\section{Multivariate logistic regression analysis for prediction of mortality}

The utility of NGAL and its kinetics for prediction of mortality were further evaluated after adjusting for other covariates. After adjusting for age, presence of acute kidney injury (AKI), and severity of illness (SAPS II), only day 3 NGAL, $\triangle$ NGAL-48, and NGALc-48 were independently predictive of mortality [Table 6].

\section{Survival analysis}

Survival analysis of NGALc-48 at a cutoff point of $-24 \%$ was analyzed [Figure 3]. There was lower survival in patients with NGALc at $48 \mathrm{~h}$ of more than $-24 \%$ compared to those with lower cutoff point ( $\log$ Mantel-Cox, $P=0.03$ ). After adjusted for age and severity of illness, patients with NGALc-48 more than $-24 \%$ were twice more likely to die at 30 days compared to those less than the cutoff point (Cox regression analysis, odds ratio 2.10 [1.05-4.18], $P=0.03$ ).

\section{Discussion}

In this prospective study, we showed that day 3 NGAL and NGAL kinetics at $48 \mathrm{~h}$ were independently predictive of

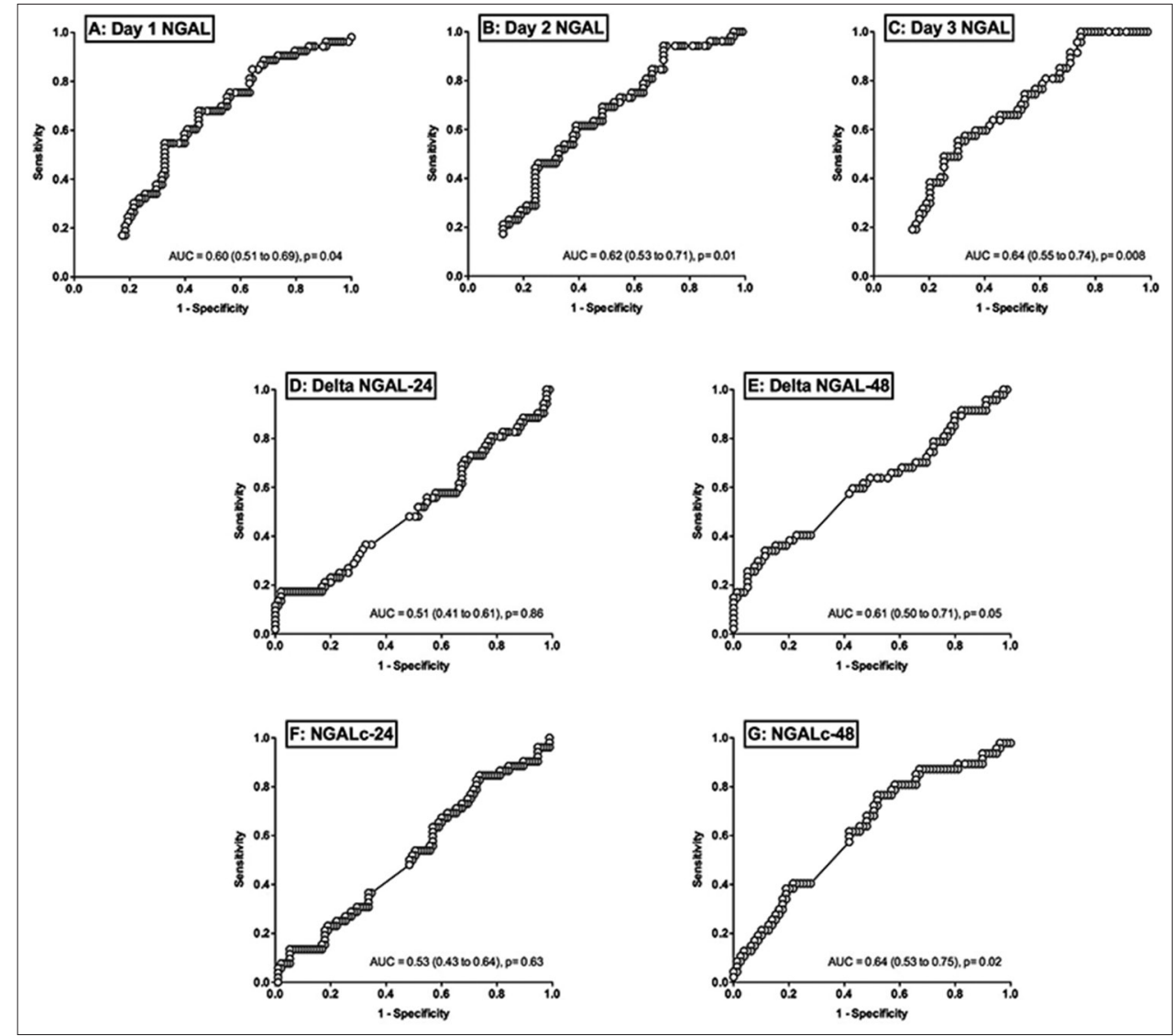

Figure 2: The area under the curve of the sensitivity over 1-specificity curve for static and dynamic neutrophil gelatinase-associated lipocalin concentration. 


\begin{tabular}{|c|c|c|c|c|}
\hline Variables & $\begin{array}{c}\text { All patients } \\
(n=151)\end{array}$ & $\begin{array}{c}\text { Survivors } \\
(n=98)\end{array}$ & $\begin{array}{c}\text { Nonsurvivors } \\
\quad(n=53)\end{array}$ & $P$ \\
\hline Age (years) & $47 \pm 17$ & $45 \pm 17$ & $51 \pm 16$ & 0.03 \\
\hline Gender (male) & $98(64.9)$ & $65(66.3)$ & $33(62.3)$ & 0.83 \\
\hline Weight (kg) & $67 \pm 13$ & $67 \pm 11$ & $66 \pm 15$ & 0.75 \\
\hline Height $(\mathrm{cm})$ & $161 \pm 8$ & $162 \pm 9$ & $161 \pm 7$ & 0.43 \\
\hline Baseline SAPS II & $43 \pm 15$ & $40 \pm 15$ & $47 \pm 15$ & 0.01 \\
\hline Baseline SOFA score & $8.0 \pm 4.0$ & $7.4 \pm 4.0$ & $9.1 \pm 3.8$ & 0.02 \\
\hline \multicolumn{5}{|l|}{ Category } \\
\hline Noninfectious SIRS & $64(42.4)$ & $43(43.9)$ & $21(39.6)$ & \multirow[t]{2}{*}{0.61} \\
\hline Sepsis & $87(57.6)$ & $55(56.1)$ & $32(60.4)$ & \\
\hline \multicolumn{5}{|l|}{ Category } \\
\hline Medical & $90(59.6)$ & $55(56.1)$ & $35(66.0)$ & \multirow[t]{2}{*}{0.24} \\
\hline Surgical & $61(40.4)$ & $43(43.9)$ & $18(34.0)$ & \\
\hline \multicolumn{5}{|c|}{ Primary admission diagnoses } \\
\hline Cardiovascular & $4(2.7)$ & $3(3.0)$ & $1(1.9)$ & \multirow[t]{10}{*}{0.65} \\
\hline Endocrine/metabolic & $4(2.6)$ & $3(3.1)$ & $1(1.9)$ & \\
\hline $\begin{array}{l}\text { Gastrointestinal/ } \\
\text { hepatobiliary/pancreas }\end{array}$ & $17(11.3)$ & $12(12.2)$ & $5(9.4)$ & \\
\hline Infective & $26(17.2)$ & $17(17.3)$ & $9(17.0)$ & \\
\hline Renal & $4(2.6)$ & $2(2.0)$ & $2(3.8)$ & \\
\hline Neurological & $18(11.9)$ & $7(7.1)$ & $11(20.8)$ & \\
\hline Respiratory & $48(31.8)$ & $33(33.7)$ & $15(28.3)$ & \\
\hline Trauma & $25(16.6)$ & $18(18.4)$ & $7(13.2)$ & \\
\hline $\begin{array}{l}\text { Connective tissue/ } \\
\text { autoimmune }\end{array}$ & $2(1.3)$ & $1(1.0)$ & $1(1.9)$ & \\
\hline Other & $3(2.0)$ & $2(2.0)$ & $1(1.9)$ & \\
\hline \multicolumn{5}{|l|}{ Comorbidity } \\
\hline Diabetes mellitus & $40(26.5)$ & $24(24.5)$ & $16(30.2)$ & 0.45 \\
\hline Hypertension & $47(31.1)$ & $31(31.6)$ & $16(30.2)$ & 0.86 \\
\hline Chronic kidney disease & $5(4.8)$ & $4(6.3)$ & $1(2.4)$ & 0.35 \\
\hline Chronic lung disease & $20(13.2)$ & $13(13.3)$ & $7(13.2)$ & 0.99 \\
\hline $\begin{array}{l}\text { Chronic cardiovascular } \\
\text { disease }\end{array}$ & $3(2.0)$ & $1(1.0)$ & $2(3.8)$ & 0.25 \\
\hline Immunosuppression & $2(1.3)$ & $0(0)$ & $2(3.8)$ & 0.05 \\
\hline Others & $11(7.3)$ & $4(4.1)$ & $7(13.2)$ & 0.04 \\
\hline Dialysis & $30(19.9)$ & $17(17.3)$ & $13(24.5)$ & 0.29 \\
\hline
\end{tabular}

\begin{tabular}{|c|c|c|c|}
\hline & $\begin{array}{c}\text { Survivors } \\
(n=98)\end{array}$ & $\begin{array}{l}\text { Nonsurvivors } \\
\quad(n=53)\end{array}$ & $P$ \\
\hline Day 1 NGAL (ng/ml) & $212(87-795)$ & $443(150-1040)$ & 0.04 \\
\hline Day 2 NGAL (ng/ml) & $190(73-458)$ & $377(130-891)$ & 0.02 \\
\hline Day 3 NGAL (ng/ml) & $201(54-607)$ & $406(136-1120)$ & 0.007 \\
\hline$\Delta$ NGAL-24 (ng/ml) & $-63 \pm 197$ & $-50 \pm 268$ & 0.75 \\
\hline$\Delta$ NGAL-48 (ng/ml) & $-76 \pm 174$ & $16 \pm 232$ & 0.01 \\
\hline NGALc-24 (\%) & $-4.1 \pm 5.2$ & $5.2 \pm 63$ & 0.32 \\
\hline NGALc-48 (\%) & $-9.6 \pm 51$ & $26 \pm 109$ & 0.01 \\
\hline
\end{tabular}

mortality in critically ill patients with SIRS. In contrast, plasma NGAL measured on ICU admission was not independently predictive of mortality. Patients with NGALc at $48 \mathrm{~h}$ at a cutoff point of $-24 \%$ were twice more likely to die compared to those at a lower cutoff point.

SIRS is due to widespread inflammation secondary to infectious or noninfectious cause. It is common in intensive care settings, occurring in more than $50 \%$ of patients admitted to the ICU, ${ }^{[1]}$ higher in surgical ICU. ${ }^{[2]}$ About one-third of SIRS patients have or eventually develop sepsis, and about 10\%-20\% died. ${ }^{[1,3]}$ In our study, mortality was higher occurring in about $30 \%$ of our patients with SIRS. Mortality rate increases as the number of SIRS criteria increases. ${ }^{[24]}$ Similarly, we showed that mortality occurred in $58 \%$ of patients with 4 SIRS criteria compared to $42 \%$ 


\begin{tabular}{|c|c|c|c|c|c|c|}
\hline & AUC (95\% CI) & $\begin{array}{c}\text { Optimal } \\
\text { cut-off point }\end{array}$ & Sensitivity & Specificity & PPV & NPV \\
\hline Day 1 NGAL & $0.60(0.51-0.69)$ & 222 & $68(55-81)$ & $55(45-65)$ & $45(34-56)$ & $76(66-86)$ \\
\hline Day 2 NGAL & $0.62(0.53-0.71)$ & 278 & $62(48-75)$ & $61(51-71)$ & $46(35-58)$ & $74(65-84)$ \\
\hline Day 3 NGAL & $0.64(0.55-0.74)$ & 319 & $57(43-72)$ & $67(57-77)$ & $51(37-64)$ & $73(62-83)$ \\
\hline$\Delta$ NGAL-24 & $0.51(0.41-0.61)$ & -14 & $50(36-64)$ & $52(42-63)$ & $37(25-49)$ & $65(54-77)$ \\
\hline$\Delta$ NGAL-48 & $0.61(0.50-0.71)$ & -6 & $49(33-64)$ & $74(63-84)$ & $51(35-67)$ & $71(61-82)$ \\
\hline NGALc-24 & $0.53(0.43-0.64)$ & -12 & $59(44-73)$ & $50(39-61)$ & $40(28-51)$ & $68(57-80)$ \\
\hline NGALc-48 & $0.64(0.53-0.75)$ & -24 & $72(58-86)$ & $54(42-65)$ & $47(34-59)$ & $77(65-89)$ \\
\hline
\end{tabular}

Data presented with 95\% CI. AUC: Area under curve; CI: Confidence interval; PPV: Positive predictive value; NPV: Negative predictive value; NGAL: Neutrophil gelatinase-associated lipocalin; NGALc: Neutrophil gelatinase-associated lipocalin clearance

\begin{tabular}{|c|c|c|c|}
\hline \multicolumn{4}{|c|}{$\begin{array}{l}\text { Table 5: The differences in the area under curve between } \\
\text { static and kinetic of neutrophil gelatinase-associated } \\
\text { lipocalin }\end{array}$} \\
\hline \multicolumn{2}{|c|}{ Comparison of AUC between } & $\begin{array}{c}\text { Differences in } \\
\text { AUC }\end{array}$ & $P$ \\
\hline \multicolumn{4}{|c|}{ Static NGAL } \\
\hline \multirow[t]{2}{*}{ Day 1 NGAL } & Day 2 NGAL & $-0.02(-0.06-0.03)$ & 0.46 \\
\hline & Day 3 NGAL & $-0.05(-0.1--0.001)$ & 0.04 \\
\hline Day 2 NGAL & Day 3 NGAL & $-0.04(-0.09-0.01)$ & 0.15 \\
\hline \multicolumn{4}{|c|}{ Dynamic NGAL } \\
\hline \multirow[t]{2}{*}{$\triangle \mathrm{NGAL}-24$} & $\Delta$ NGAL-48 & $0.12(0.01-0.23)$ & 0.03 \\
\hline & NGALc-24 & $0.02(-0.02-0.05)$ & 0.44 \\
\hline NGALc-24 & NGALc-48 & $0.12(0.01-0.23)$ & 0.03 \\
\hline$\Delta$ NGAL-48 & NGALc-48 & $0.02(-0.02-0.07)$ & 0.48 \\
\hline \multicolumn{4}{|c|}{ Static versus dynamic NGAL } \\
\hline \multirow[t]{4}{*}{ Day 1 NGAL } & $\triangle \mathrm{NGAL}-24$ & $-0.09(-0.24-0.06)$ & 0.24 \\
\hline & $\Delta$ NGAL-48 & $0.02(-0.14-0.18)$ & 0.80 \\
\hline & NGALc-24 & $-0.08(-0.23-0.08)$ & 0.33 \\
\hline & NGALc-48 & $0.04(-0.12-0.2)$ & 0.61 \\
\hline \multirow[t]{4}{*}{ Day 2 NGAL } & $\triangle \mathrm{NGAL}-24$ & $-0.11(-0.24-0.014)$ & 0.08 \\
\hline & $\Delta$ NGAL-48 & $-0.003(-0.15-0.14)$ & 0.97 \\
\hline & NGALc-24 & $-0.10(-0.22-0.03)$ & 0.12 \\
\hline & NGALc-48 & $0.016(-0.13-0.16)$ & 0.82 \\
\hline \multirow[t]{4}{*}{ Day 3 NGAL } & $\triangle \mathrm{NGAL}-24$ & $-0.15(-0.3--0.008)$ & 0.04 \\
\hline & $\Delta$ NGAL-48 & $-0.03(-0.16--0.10)$ & 0.63 \\
\hline & NGALc-24 & $-0.14(-0.28-0.005)$ & 0.06 \\
\hline & NGALc-48 & $-0.01(-0.13-0.1)$ & 0.82 \\
\hline
\end{tabular}

Comparison of AUC was analyzed using DeLong method.

NGAL: Neutrophil gelatinase-associated lipocalin; NGALc: Neutrophil gelatinase-associated lipocalin clearance; AUC: Area under curve

in those with 3 SIRS criteria and $28 \%$ with 2 SIRS criteria. The differences in mortality were significant between 2 and 4 SIRS criteria $(P=0.04)$. Hence, early risk stratification in SIRS patients is important to reduce mortality. This could alert an intensivist for reevaluation or intensification of therapy, for example, early dialysis, modification of antimicrobial therapy, or the need for additional diagnosis measures, which could prevent progression of organ failure and the associated increased in mortality. ${ }^{[18]}$

Biomarkers could assist in risk stratification of critically ill patients. Plasma NGAL is a small molecule of $25 \mathrm{kDa}$. It has

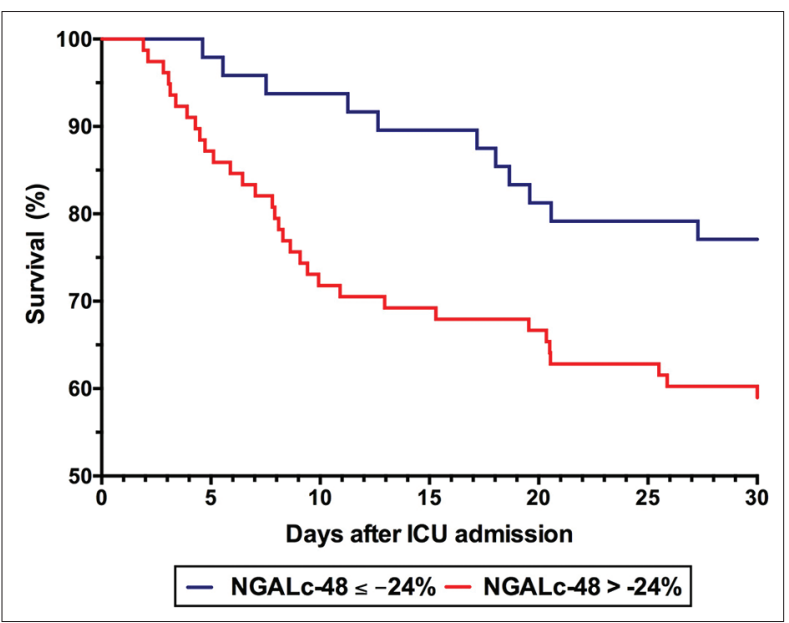

Figure 3: Survival analysis of neutrophil gelatinase-associated lipocalin clearance at 48 at a cutoff point of $-24 \%$. Patients with neutrophil gelatinase-associated lipocalin clearance at $48 \mathrm{~h}$ of more than $-24 \%$ were more likely to die within 30 days compared to those with lower cutoff point (log Mantel-Cox, $P=0.03$ ).

been investigated as a biomarker of sepsis ${ }^{[13]}$ and AKI and prediction of mortality. ${ }^{[14,15,17]}$ Most studies investigated the value of single time point measurement of biomarker. This may be of limited value due to variability of biomarker secretion at different phases of critical illness and unknown time lapsed between insult and ICU admission. ${ }^{[18]}$ We showed that plasma NGAL measured on ICU admission was not predictive of mortality after adjusting for age, presence of AKI, and severity of illness. In contrast, plasma NGAL measured after $48 \mathrm{~h}$ was independently predictive with an odds ratio of 2.58 (1.26-5.29). AKI was included as covariates as it correlates with an increase in NGAL concentration. ${ }^{[14]}$

We showed that day 3 NGAL and NGAL kinetics at $48 \mathrm{~h}$ were moderately predictive of mortality with AUC of $>0.60$. The AUC is a measure of discrimination that is how well a given test (e.g., a new biomarker) separates those with and without disease as determined by the gold standard ${ }^{[25]}$ It ranges from 0.5 (no discrimination) to 1 (perfect discrimination). ${ }^{[25,26]}$ Clinical validity is assumed at an AUC of more than 0.70 . Hence, AUC of day $3 \mathrm{NGAL}$ and NGAL kinetics at $48 \mathrm{~h}$ of 0.64 is not assumed to be predictive of mortality. In addition, 


\begin{tabular}{|c|c|c|}
\hline Variables & OR (95\% Cl) & $P$ \\
\hline Age & $0.97(0.93-1.02)$ & 0.29 \\
\hline SAPS II (without renal score) & $1.09(1.00-1.18)$ & 0.06 \\
\hline Acute kidney injury & $3.60(0.63-20.6)$ & 0.15 \\
\hline Day 1 NGAL & $1.59(0.70-3.64)$ & 0.27 \\
\hline Day 2 NGAL & $2.14(0.86-5.35)$ & 0.10 \\
\hline Day 3 NGAL & $3.64(1.41-9.37)$ & 0.007 \\
\hline$\triangle$ NGAL-24 & $1.70(0.54-5.34)$ & 0.37 \\
\hline$\Delta$ NGAL-48 & $12.0(1.97-73.4)$ & 0.007 \\
\hline NGALc-24 & $2.15(0.57-8.16)$ & 0.26 \\
\hline NGALc-48 & $5.34(1.11-25.6)$ & 0.04 \\
\hline
\end{tabular}

All NGAL values are log-transformed. Data expressed at OR with 95\% CI. Acute kidney injury defined by creatinine $>50 \%$ of first admission creatinine or urine output of $<0.5 \mathrm{ml} / \mathrm{kg} / \mathrm{h}$ for $6 \mathrm{~h}$. NGAL data were entered separately. NGAL: Neutrophil gelatinase-associated lipocalin; NGALc: Neutrophil gelatinase-associated lipocalin clearance; OR: Odds ratio; CI: Confidence interval; SAPS: Simplified Acute Physiological Score

differences between the AUC of static versus dynamic NGAL was only significant between day 3 and $\triangle$ NGAL-24. However, the main limitation of the AUC is that its calculation is based on rank, merely considering the comparative rank between those with and without the disease. It does not take into account the extent of change of the biomarker or its distribution. Any change of rank in those at low distribution will have the same impact in those at high distribution. ${ }^{[25]}$

The additional value of a new biomarker to an available clinical diagnostic or predictor assessment (the reference model) may be better assessed by the multivariate logistic regression analysis. NGAL kinetics has an added value in reference to the SAPS II for prediction of mortality. This is shown in the multivariate logistic regression analysis which showed that NGAL kinetics at $48 \mathrm{~h}$ predicted mortality even after adjusted for SAPS II. We did not include both SOFA and SAPS II as both contain almost similar parameters and are strongly correlated $(r=0.718, P<0.0001)$.

Serial measurement of biomarker allows assessment of dynamic changes. Dynamic changes of biomarker had been shown to better predict outcome such as mortality compared to a single time point collection. The added value of calculating the dynamic changes of biomarker is that it integrates change over time, which captures function of both severity and duration of injury. Dynamic changes of creatinine, procalcitonin, and urinary cystatin $\mathrm{C}$ had been shown to be predictive of outcome. ${ }^{[16-18]}$ The extent of changes in NGAL may be influenced by its baseline concentration as has been shown previously that NGAL was higher in patients with sepsis compared to SIRS. ${ }^{[13,15]}$ To adjust for this, we calculated the relative changes of NGAL in relation to day 1 plasma NGAL. We showed that both the actual and relative dynamic changes of NGAL after $48 \mathrm{~h}$ were independently predictive of mortality.

The cutoff point of NGALc or its dynamic changes is of interest as this could assist clinicians in identifying at-risk patient. We showed that patients with $48 \mathrm{~h} \mathrm{NGALc}$ of more than $-24 \%$ were twice more likely to die compared to those with clearance of less than the cutoff point. From this, we suggest that NGAL could be measured on admission and repeated $48 \mathrm{~h}$ later to assist in identifying at-risk patients who may benefit from reevaluation and intensification of therapy.

\section{Study limitations}

The study has several limitations. First, it was conducted at a single center with a small sample size. Second, the strict inclusion criteria of patients with SIRS in this study limit generalizability of the finding to other patient groups in the ICU. Finally, NGAL was measured within $24 \mathrm{~h}$ of ICU admission. Measurement within 2-4 h may capture earlier changes that occur with the kidney cellular injury. However, a study had shown that there was no difference in NGAL performance when measured earlier at the emergency department or later in the ICU. ${ }^{[14]}$

\section{Conclusions}

NGAL kinetics and its dynamics over $48 \mathrm{~h}$ were independently predicted mortality in critically ill patients with SIRS. Patients with NGALc at $48 \mathrm{~h}$ at a cutoff point of more than $-24 \%$ were twice more likely to die compared to those at a lower cutoff point. This could assist clinicians in risk stratification of this group of high-risk patients.

\section{Acknowledgments}

We would like to thank Siti Nabilah Zainuddin, Hismayanti Ghazali, Diana Hafiza Ghazali, and Nurhafizah Zairudin for their assistance in data collection for the study. Abstract of this presentation has been presented at the Malaysian Society of Anaesthesiologists Annual Scientific Congress 2016 and has been awarded with the MSA Award 2016.

\section{Financial support and sponsorship}

This study was funded by the Ministry of Higher Education Fundamental Research Grant Scheme (FRGS/1/2015/SKK02/ UIAM/02/3).

\section{Conflicts of interest}

There are no conflicts of interest.

\section{References}

1. Brun-Buisson C. The epidemiology of the systemic inflammatory response. Intensive Care Med 2000;26 Suppl 1:S64-74.

2. Pittet D, Rangel-Frausto S, Li N, Tarara D, Costigan M, Rempe L, et al. Systemic inflammatory response syndrome, sepsis, severe sepsis and septic shock: Incidence, morbidities and outcomes in surgical ICU patients. Intensive Care Med 1995;21:302-9.

3. Qiu H, Du B, Liu D. Clinical study of systemic inflammatory response syndrome and multiple organ dysfunction syndrome in critically patients. Zhonghua Wai Ke Za Zhi 1997;35:402-5.

4. Soni SS, Cruz D, Bobek I, Chionh CY, Nalesso F, Lentini P, et al. NGAL: A biomarker of acute kidney injury and other systemic conditions. Int Urol Nephrol 2009;42:141-50.

5. Bolignano D, Donato V, Coppolino G, Campo S, Buemi A, Lacquaniti A, et al. Neutrophil gelatinase-associated lipocalin (NGAL) as a marker of kidney damage. Am J Kidney Dis 2008;52:595-605. 
6. Schmidt-Ott KM, Mori K, Li JY, Kalandadze A, Cohen DJ, Devarajan P, et al. Dual action of neutrophil gelatinase-associated lipocalin. J Am Soc Nephrol 2007;18:407-13.

7. Clerico A, Galli C, Fortunato A, Ronco C. Neutrophil gelatinase-associated lipocalin (NGAL) as biomarker of acute kidney injury: A review of the laboratory characteristics and clinical evidences. Clin Chem Lab Med 2012;50:1505-17.

8. Devarajan P. Emerging biomarkers of acute kidney injury. Contrib Nephrol 2007;156:203-12.

9. Shapiro NI, Trzeciak S, Hollander JE, Birkhahn R, Otero R, Osborn TM, et al. A prospective, multicenter derivation of a biomarker panel to assess risk of organ dysfunction, shock, and death in emergency department patients with suspected sepsis. Crit Care Med 2009;37:96-104.

10. Bagshaw SM, Bennett M, Haase M, Haase-Fielitz A, Egi M, Morimatsu $\mathrm{H}$, et al. Plasma and urine neutrophil gelatinase-associated lipocalin in septic versus non-septic acute kidney injury in critical illness. Intensive Care Med 2010;36:452-61.

11. Mårtensson J, Bell M, Xu S, Bottai M, Ravn B, Venge P, et al. Association of plasma neutrophil gelatinase-associated lipocalin (NGAL) with sepsis and acute kidney dysfunction. Biomarkers 2013;18:349-56.

12. de Geus HR, Bakker J, Lesaffre EM, le Noble JL. Neutrophil gelatinase-associated lipocalin at ICU admission predicts for acute kidney injury in adult patients. Am J Respir Crit Care Med 2011;183:907-14.

13. Shapiro NI, Trzeciak S, Hollander JE, Birkhahn R, Otero R, Osborn TM, et al. The diagnostic accuracy of plasma neutrophil gelatinase-associated lipocalin in the prediction of acute kidney injury in emergency department patients with suspected sepsis. Ann Emerg Med 2010;56:52-9.e1

14. Ralib AM, Pickering JW, Shaw GM, Than MP, George PM, Endre ZH, et al. The clinical utility window for acute kidney injury biomarkers in the critically ill. Crit Care 2014;18:601.

15. Md Ralib A, Mat Nor MB, Pickering JW. Plasma neutrophil gelatinase associated lipocalin diagnosed acute kidney injury in patients with systemic inflammatory disease and sepsis. Nephrology (Carlton) 2016 Apr 8. doi: 10.1111/nep.12796 [Epub ahead of print].

16. Pickering JW, Frampton CM, Endre ZH. Evaluation of trial outcomes in acute kidney injury by creatinine modeling. Clin J Am Soc Nephrol 2009;4:1705-15.

17. Ralib AM, Pickering JW, Shaw GM, Devarajan P, Edelstein CL, Bonventre JV, et al. Test characteristics of urinary biomarkers depend on quantitation method in acute kidney injury. J Am Soc Nephrol 2012;23:322-33.

18. Mat Nor MB, Md Ralib A. Procalcitonin clearance for early prediction of survival in critically ill patients with severe sepsis. Crit Care Res Pract 2014;2014:819034.

19. Levy MM, Fink MP, Marshall JC, Abraham E, Angus D, Cook D, et al. $2001 \mathrm{SCCM} / \mathrm{ESICM} / \mathrm{ACCP} / \mathrm{ATS} / \mathrm{SIS}$ international sepsis definitions conference. Crit Care Med 2003;31:1250-6.

20. Dent CL, Ma Q, Dastrala S, Bennett M, Mitsnefes MM, Barasch J, et al. Plasma neutrophil gelatinase-associated lipocalin predicts acute kidney injury, morbidity and mortality after pediatric cardiac surgery: A prospective uncontrolled cohort study. Crit Care 2007;11:R127.

21. Hanley JA, McNeil BJ. The meaning and use of the area under a receiver operating characteristic (ROC) curve. Radiology 1982;143:29-36.

22. Fluss R, Faraggi D, Reiser B. Estimation of the Youden Index and its associated cutoff point. Biom J 2005;47:458-72.

23. DeLong ER, DeLong DM, Clarke-Pearson DL. Comparing the areas under two or more correlated receiver operating characteristic curves: A nonparametric approach. Biometrics 1988;44:837-45.

24. Rangel-Frausto MS, Pittet D, Costigan M, Hwang T, Davis CS, Wenzel RP. The natural history of the systemic inflammatory response syndrome (SIRS). A prospective study. JAMA 1995;273:117-23.

25. Cook NR. Use and misuse of the receiver operating characteristic curve in risk prediction. Circulation 2007:115:928-35.

26. Bewick V, Cheek L, Ball J. Statistics review 13: Receiver operating characteristic curves. Crit Care 2004;8:508-12. 